\title{
Gear Bending Stress Analysis of Automatic Transmissions with Different Fillet Curves
}

\author{
Gang $\mathrm{Li}^{1 *}$ and Zhi Geng ${ }^{2}$ \\ 0000-0003-2793-4615, 0000-0002-4513-9984 \\ ${ }^{1}$ Department of Mechanical Engineering, University of Maryland Baltimore County, Baltimore MD, 21250, United States \\ ${ }^{2}$ Shanghai Lanzai Information Technology Co., Ltd, Pudong, Shanghai, 200120, China
}

\begin{abstract}
Gear bending strength is a core indicator to indicate reliability and operation performances of automotive transmissions. Fillet curve design of dedendum of gear teeth can improve their bending stress and complex tooth contact performance. Geometrical parameters of gears are considered important for the variation of stresses in the design of gears. Bending stress analysis has been a key area of research to minimize failure and optimize design. This work presents a finite element (FE)-based analysis method of gear bending stress, which can be used for multiple spatial meshing gear teeth simultaneously. Three-dimensional (3D) models of helical gear with double and single circular fillet curves are established by using Pro/ENGINEER. By changing of meshing positions of gears, tooth contact analysis results along their paths of contact are obtained. Since FE-based tooth contact analysis are performed based on 3D models, the results of bending stress are reliable and authoritative. It is proved that bending stress of the gear with double circular fillet curves is $1.3 \sim 1.5$ times as that of the gear with single circular fillet curves, which means that gear with single circular fillet curves has better loading capacity than gear with double circular fillet curves. The study will provide a good method for studying gear bending stress to improve gear design of automotive transmissions.
\end{abstract}

Keywords: Involute gears; Bending stress; Finite element analysis; Fillet curves

\author{
Research Article \\ https://doi.org/10.30939/ijastech..887588
}

Received 01.03.2021

Revised 07.04.2021

Accepted $\quad 07.04 .2021$

* Corresponding author

Gang Li

gangli@umbc.edu

Address: Department of Mechanical Engineering, University of Maryland Baltimore County, Baltimore, MD, USA

Tel: +1 410-455-3309

\section{Introduction}

Gearing is one of the most efficient methods for power transmission from one shaft to another with or without changing their rotation speeds. Involute gears are the most common type of gears, which are widely used in many applications, such as automobile, robotics, and renewable energy industry [1-3]. Gear transmissions can provide reliable power conversion from a prime mover, such as an engine and an electric motor, to a driven part, such as a wheel and a chain, with a continuous output-to-input speed ratio [4,5]. Gears have various types according to their tooth profiles and tooth widths, and have a wide range of dimensions as small as the ones in small appliances to the very large gears used in heavy-duty applications [6,7]. Generally, gears are manufactured via hobbing [8] or forming cutting [9-11] based on the theory of gearing. For some gears with special tooth profiles, e.g., concave-convex and spiral tooth profiles, their manufacturing methods and machine-tools are complex. Since meshing performances of these gears with special tooth profiles are highly sensitive to manufacturing errors [12,13], high manufacturing accuracy of gear machine-tools is required for these gears [14-16].

Meshing performances of gear systems are important for reliability of gear transmissions. Contact patterns and transmission errors are two typical methods for meshing performance evaluation of gear systems [17-19]. A tooth profile modeling method was developed to improve accuracy of tooth contact analysis for gear tooth profiles [20]. Some other meshing performances, e.g., power losses, can also be evaluated based tooth contact analysis [21,22]. Since these gears have single circular fillet curves, they cannot be manufactured via standard gear manufacturing methods. During a manufacture in this way, for each of the gear modules and the radius of curvature, a different blade size and gear holder is needed. However, it's clear that these gears have many advantages, if they can be produced sufficiently in the industry [23-25]. Since these gears have better load-bearing capabilities, have a balancing feature for the axial forces, quiet operation feature and their lubrication characteristics of gear with single circular fillet curves are better than gear with double circular fillet curves. It's noteworthy that there are number of studies carried out recently in relation to these gears. 
Some studies focus on influences of fillet curves on bending strength of involute spur gears. One of the reasons is that analysis of gear bending strength becomes more difficult when several gear teeth are contacting in space simultaneously, especially for modified helical gears [5,26]. However, dedendum single circular gears have been used in most of gearboxes in Japan, also in some gearboxes. It turns out that this kind of gear is better. However, due to the lack of theoretical supports, dedendum single circular gears are not widely used in practical applications. So it is very significant for us to analyze influences of different fillet curves on gear bending strength.

The remaining part of this paper is organized as follows: a bending stress model of helical gears is developed in Sec. 2. Finite element modeling of helical gears with different fillet curves is introduced in Sec. 3. The bending stress analysis process is performed in Sec. 4. Some finite element analysis of bending stress of helical gears are presented in Sec. 5. Finally, some conclusions from this study are presented in Sec. 6.

\section{Bending Stress Model of Gear Tooth Surfaces}

Generally, tooth profiles of a helical gear are involute spiral surfaces, which are designed by countless involutes along a spiral curve. Hence, modeling of gear tooth profiles is the key step to accurately design involute, helix, and fillet curves [27].

In this study, two types of helical gears with different typical fillet curves were studied. The hobbing generation method of helical gears is introduced by using rack cutters with different fillet curves. Involute tooth profiles of helical gears are formed by straight parts of two rack cutters. Fillet curves of helical gears are formed by circular parts of two rack cutters. For helical gears with double circular fillet curves, the radius of its fillet curve is $0.38 m_{n}$, where $m_{n}$ is the normal module. For helical gears with single circular fillet curves, its fillet curve is a whole circular whose starting point is the meshing point intersected by involute and gear top, and tangent to dedendum circle, as shown in Fig. 1. Three-dimensional (3D) models of helical gears with single circular and double circular fillet curves are shown in Fig. 2. The basic geometrical parameters of helical gears in this study are listed in Table 1. Design parameters of gear fillet curves of helical gears with single circular and double circular fillet curves are provided in Table 2.

Table 1. Basic geometry parameters of helical gears.

\begin{tabular}{c|c}
\hline Parameters & Values \\
\hline Number of teeth & Pinion: 20; Gear: 41 \\
\hline Normal module $(\mathrm{mm})$ & 12 \\
\hline Normal pressure angle $\left(^{\circ}\right)$ & 17.5 \\
\hline Spiral angle $\left(^{\circ}\right)$ & 32 \\
\hline Face width $(\mathrm{mm})$ & 20 \\
\hline Material & 16Ni3CrMoE \\
\hline Hardness of the carburized layer & $\geq 800 \mathrm{HV}$ \\
\hline Young's modulus $(\mathrm{GPa})$ & 250 \\
\hline Poisson's ratio & 0.3 \\
\hline
\end{tabular}

Table 2 Design parameters of gear fillet curves of helical gears

\begin{tabular}{c|c}
\hline Items & Values \\
\hline Dedendum (mm) & 2 \\
\hline Modification coefficient & 0.2 \\
\hline $\begin{array}{c}\text { Radius of single circular fillet } \\
\text { curves (mm) }\end{array}$ & 2.4 \\
\hline $\begin{array}{c}\text { Radius of single circular fillet } \\
\text { curves (mm) }\end{array}$ & 0.4 \\
\hline
\end{tabular}

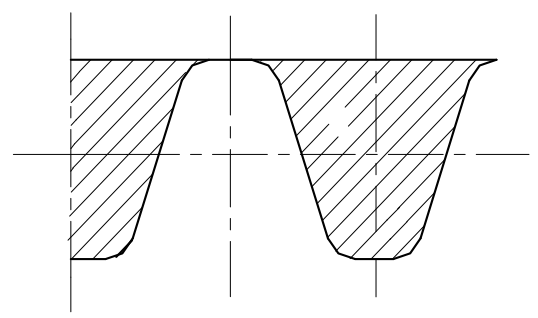

(a) Cutter shape for helical gears with double circular fillet curves

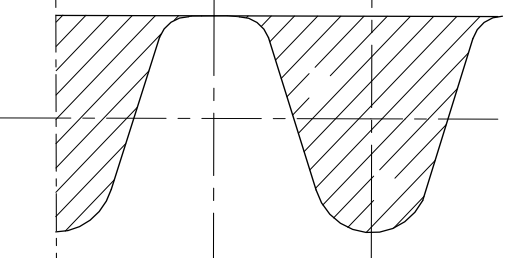

(b) Cutter shape for helical gears with single circular fillet curves

Fig. 1. Tooth shapes of rack cutters for helical gears with single circular and double circular fillet curves

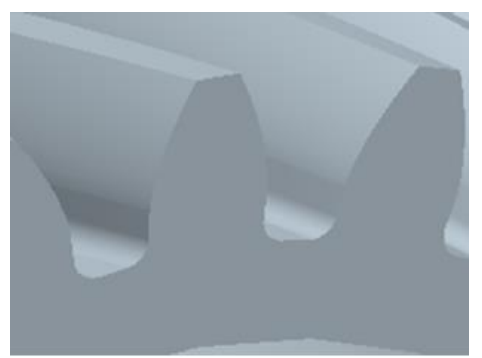

(a) Helical gears with double circular fillet curves

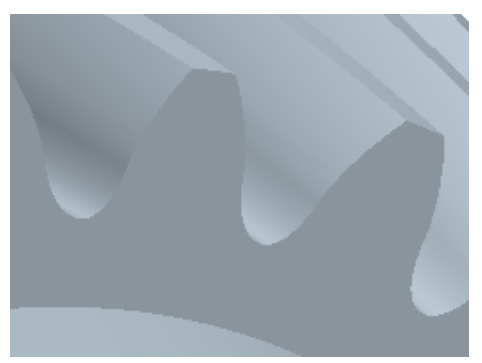

(b) Helical gears with single circular fillet curves

Fig. 2. 3D models of helical gears with single circular and double circular fillet curves 


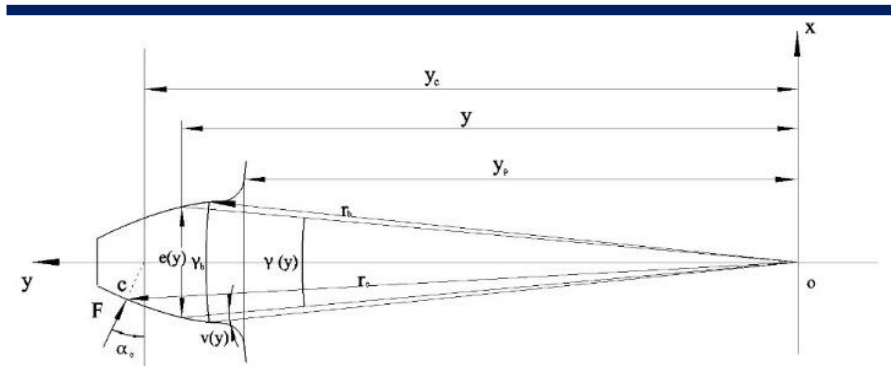

Fig. 3. Geometric parameters of an involute gear tooth

A tooth model of a helical gear is used to describe its geometric parameters [28], as shown in Fig. 3. The base central angle $\gamma_{b}$ of a tooth can be represented as

$$
\gamma_{b}=\frac{\pi}{z}+\frac{4 \chi}{z} \tan \alpha_{n}+2\left(\tan \alpha_{t}-\alpha_{t}\right)
$$

where $z$ is the number of teeth, $\alpha_{t}$ and $\alpha_{n}$ are the transverse pressure angle and the normal pressure angle, respectively, and $\chi$ is the addendum coefficient. The pressure angle $\alpha_{c}$ at the contact point can be represented as

$$
\alpha_{c}=\frac{2 \pi}{z} \xi_{c}-\frac{\gamma_{b}}{2}
$$

where $\xi_{c}$ is the profile parameter of the contact point that can be represented as

$$
\xi_{c}=\frac{z}{2 \pi} \sqrt{\frac{r_{c}^{2}}{r_{b}^{2}}-1}
$$

in which $r_{b}$ is the base radius and $r_{c}$ is the profile radius of the contact point. The tooth central angle $\gamma(y)$ can be represented as

$$
\gamma(y)=\gamma_{b}-2 v(y)
$$

where $v(y)$ is the tooth profile angle.

A load distribution model of helical gears is used in this study based on the minimum elastic potential energy theory [29]. The elastic potential energy of a helical gear tooth is composed of a bending component $U_{x}$, a compressive component $U_{n}$ and a shear component $U_{s}$ :

$$
U=U_{x}+U_{n}+U_{s}
$$

where $U_{x}, U_{n}$ and $U_{s}$ can be represented as

$$
\left\{\begin{array}{l}
U_{x}=6 \frac{F^{2} \cos ^{2} \alpha_{c}}{E B} \int_{y_{p}}^{y_{c}} \frac{\left(y_{c}-y\right)^{2}}{e^{3}(y)} \mathrm{d} y \\
U_{n}=6 \frac{F^{2} \sin ^{2} \alpha_{c}}{E B} \int_{y_{p}}^{y_{c}} \frac{1}{e(y)} \mathrm{d} y \\
U_{s}=\frac{C F^{2} \cos ^{2} \alpha_{c}}{2 G B} \int_{y_{p}}^{y_{c}} \frac{1}{e(y)} \mathrm{d} y
\end{array}\right.
$$

in which $F$ is the normal load, $F=10^{3} P / \omega r_{b}, P$ is the transmitted power, $\omega$ is the angular velocity of the pinion, $B$ is the tooth width, $E$ is the modulus of elasticity, $C$ is the shear potential correction factor, $G$ is the transverse modulus of elasticity, $y_{p}$ is the $y$ coordinate of the intersection of the root circle and the $y$ axis, $y_{c}$ is the $y$ coordinate of a contact point and

$$
e(y)=2 r(y) \sin \frac{\gamma(y)}{2}
$$

Suppose that there are $\hat{n}$ pairs of meshing teeth at a time instant; the normal load acting on the $\hat{i}$ th tooth surface can be represented as

$$
F_{\hat{i}} \xi=\frac{\frac{1}{U_{\hat{i}}}}{\sum_{\hat{j}=1}^{\hat{n}} \frac{1}{U_{\hat{j}}}} F=\frac{V_{\hat{i}}}{\sum_{\hat{j}=1}^{\hat{n}} V_{\hat{j}}} F
$$

where $U_{\hat{i}}$ and $U_{\hat{j}}$ are elastic potential energies of the $\hat{i}$ th and $\hat{j}$ th meshing tooth surfaces, respectively, and $V_{\hat{i}}$ and $V_{\hat{j}}$ are inverses of elastic potential energies of the $\hat{i}$ th and $\hat{j}$ th meshing tooth surfaces, respectively. The elastic potential energy $U_{\hat{i}}$ of the $\hat{i}$ th meshing tooth surface can be represented as

$$
U_{\hat{i}}=\frac{l_{c \hat{i}}}{\sum_{\hat{j}=1}^{\hat{n}} l_{c \hat{j}}} U
$$

where $l_{c \hat{i}}$ and $l_{c \hat{j}}$ are lengths of contact lines of the $\hat{i}$ th and $\hat{j}$ th meshing tooth surfaces, respectively. The involute rack gear tooth is divided into slices with unit lengths. The load acting on the $\hat{k}$ th slice can be represented as

$$
f_{\hat{k}} \xi=\frac{\varepsilon_{\beta} \cos \beta_{b}}{B} \frac{V_{\hat{k}} \xi}{\int_{l_{c i}} V_{\hat{k}} \xi \mathrm{d} l_{c i}} F_{\hat{i}} \xi
$$

where $\varepsilon_{\beta}$ is the face contact ratio, $\beta_{b}$ is the base spiral angle, and $V_{\hat{k}}$ is the inverse of the elastic potential energy of the $\hat{k}$ th slice.

When teeth mesh, the load is delivered to the teeth with a certain impact. If we simply calculate the bending stress, the velocity factor should be used in the calculation [16]. The tooth bending stress of helical gears can be represented as

$$
\sigma_{b}=\frac{0.93 K_{v} K_{o} K_{s} K_{m} \int_{l_{c i}} f_{\hat{k}}(\xi) \mathrm{d} l_{c i}}{B m_{n} Y_{j}}
$$

where $Y_{j}$ is the geometric factor, $K_{v}$ is the dynamic velocity factor, $K_{o}$ is the overload factor, $K_{s}$ is the size factor, and $K_{m}$ is the load distribution factor.

\section{Finite Element (FE) Modeling of Helical Gears with Dif- ferent Fillet Curves}




\subsection{Grid feature and classification}

In finite element analysis (FEA), the sizes of grid meshes of gear tooth surfaces are relative to accuracy of FEA results of their contact stress [30]. In this work, a P-method of Pro/ENGINEER Mechanica is used for meshing finite element models of the helical gear pair, which can fit complex geometric shapes accurately and improve accuracy of convergence by improving the deformation polynomial equation (highest 9 order) automatically while not changing size of grid meshes, although the sizes of meshes are bigger than non-adaptive $\mathrm{H}$-method. In order to balance calculation speed and analysis accuracy, we refined some parts of the gears, such as the area near fillet curves, tooth contacting area and so on, for the rest automatic grid partition is adopted.

\subsection{Settings of boundary condition, loads and contacts}

For the gear of the helical gear pair, limit all DOFs of its axis apertures, and for the pinion, limit the DOFs of radial and axial movement referring to the cylindrical coordinate system, which is generated considering rotary center as a benchmark. Setting the torque $T=256 \mathrm{Nm}$ and the rotation speed $w=20 \mathrm{rpm}$ of the pinion and contact conditions on tooth surfaces of three meshing gear teeth, which may contact. Since Pro/ENGINEER Mechanica can imitate natural physical contact characteristics, it can automatically find contact areas of tooth surfaces that mesh under the loading condition. Hence, a pair of finite element models are constructed in this study, which are contacting in space as shown in Fig. 4. Hence, boundary conditions of helical gear pairs do not change with their rotation.

\section{Bending Stress Analysis}

Since 3D finite element models were adopted based on space contacts, it becomes easy to get bending stress of the whole tooth surface. In order to make comparison results authoritative and reliable, we made convergence analysis as follows. Generally, the accuracy of analysis results has much to do with size of grid cells, so it becomes necessary for us to do it. Figure 5 shows the gradual refined grids of a dedendum single circular gears and partial enlarged details of dedendum parts.

Moreover, two cases were considered when choosing comparative data, one is the maximum principal stress on the tension side of the tooth, where gear is more likely to be damaged, another is first principal stress on the tangent connected by countless points, every one of which is gotten through intersection of tooth shape and diagonal lines on gear tooth surfaces, according to the $30^{\circ}$ standards, so the graphics of them are intuitive and representative, as shown in Fig. 6. Meanwhile, considering the fact that stress on tangent may not include the maximum of tooth root stress, the maximum principal stress of the gear has been studied later. Mesh refining results of tooth surface of helical gears with single fillet curves are listed in Table 3.

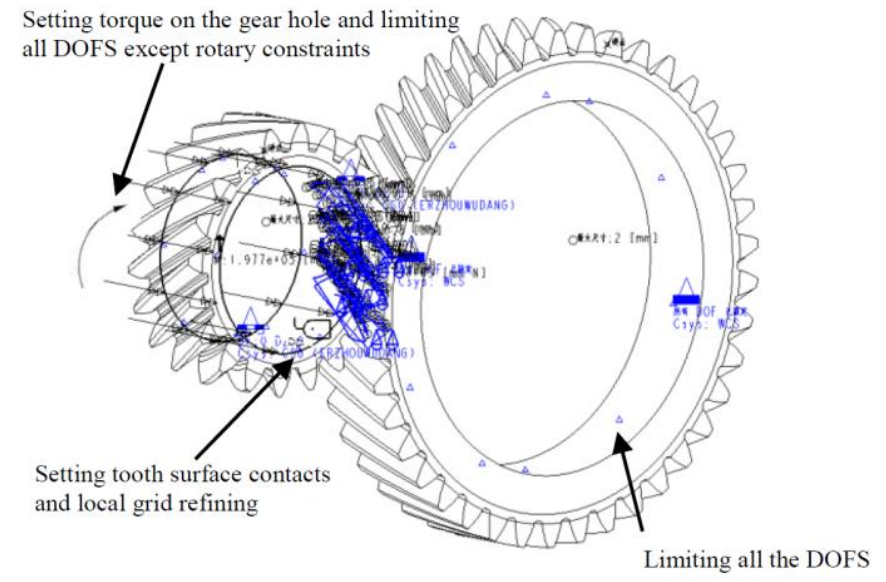

Fig. 4. Gear assembly model with constraints, loads and tooth contacts

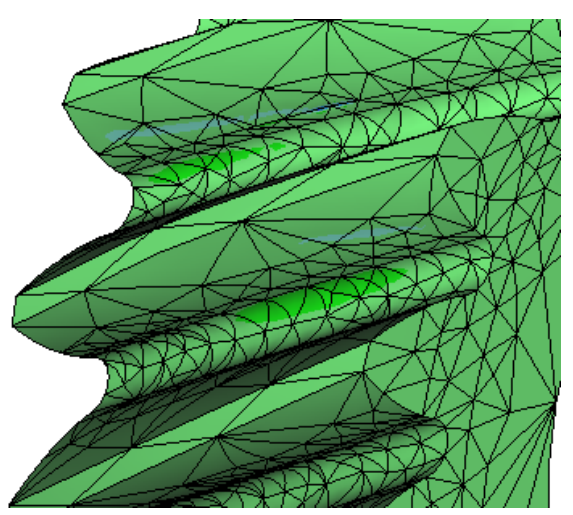

Fig. 5. Meshes of the FE model of the helical gear

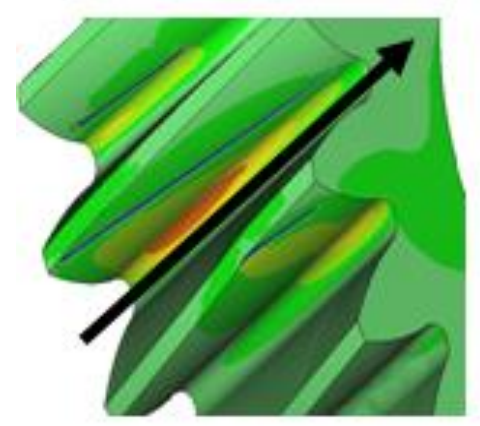

Fig. 6. The position of tooth root tangent

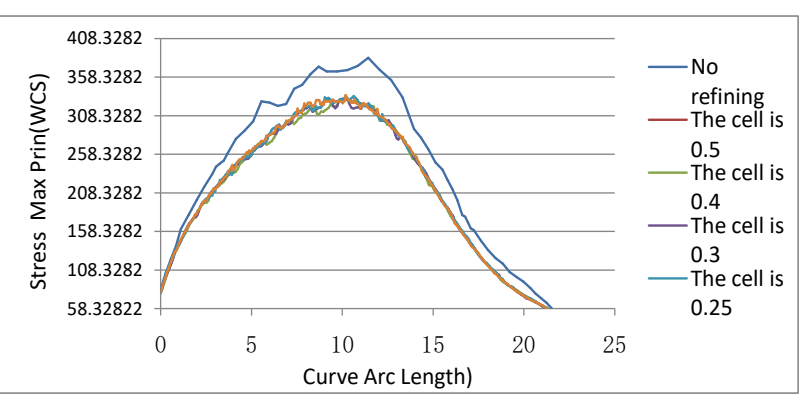

Fig. 7. Bending stress of the tooth root 
Table 3 Mesh refining results of tooth surface of helical gears with single fillet curves

\begin{tabular}{c|c|c}
\hline Mesh Size & Number of Elements & Max Principle Stress \\
\hline No Refining & 30725 & $519.0 \mathrm{Mpa}$ \\
\hline $0.5 \mathrm{~mm}$ & 72682 & $489.2 \mathrm{Mpa}$ \\
\hline $0.4 \mathrm{~mm}$ & 91205 & $493.4 \mathrm{Mpa}$ \\
\hline $0.3 \mathrm{~mm}$ & 123013 & $498.3 \mathrm{Mpa}$ \\
\hline $0.25 \mathrm{~mm}$ & 158865 & $498.8 \mathrm{Mpa}$ \\
\hline $0.2 \mathrm{~mm}$ & 220889 & $498.6 \mathrm{Mpa}$ \\
\hline
\end{tabular}

Figure 7 shows changes of maximum principal stress on the tangent before and after mesh refinement, before refinement stress is large, while after it stress becomes smaller, and it remain the same after several mesh refinements, so five curves in Fig. 7 almost keep coincident. It proves the result converged. At last, considering the relationship between calculation accuracy and time, grid cell is set 0.3 in the following operations.

\section{Analysis and Comparison of Bending Stress}

In the process of gear transmission, meshing times of the big gear is less than the small one's at the same time, that is the big gear has better fatigue strength, so in this paper, the small gear is considered as a research object to analysis changes of its bending stress.

\subsection{Meshing process simulation of helical gears}

Figures 8 and 9 show the first principal stress cloud charts and partial enlargement diagrams of the two kinds of gears (dedendum double circular gears and dedendum single circular gears) at one moment of engagement process. Figure 4 shows that there are three teeth contacting with each other at that moment and bending stress of dedendum single circular gears is smaller than that of dedendum double circular gears obviously (one is $689 \mathrm{Mpa}$, while the other is only $489 \mathrm{Mpa}$ ). With Gear meshing position changing constantly, bending stress changed. In this paper, the pair of gears we studied rotated for 18 times (an engagement period), and $1^{\circ}$ every time, so the whole process of gear engagement can be simulated accurately.

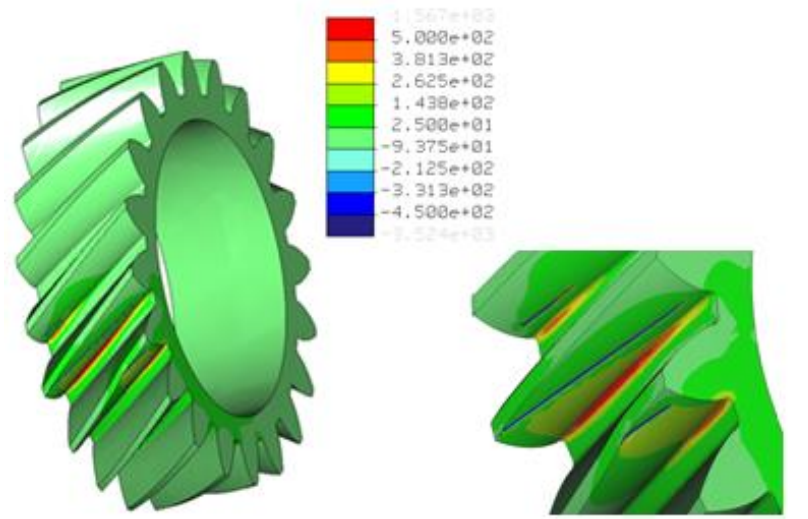

Fig. 8. Distribution of tooth root stress of dedendum double circular gear

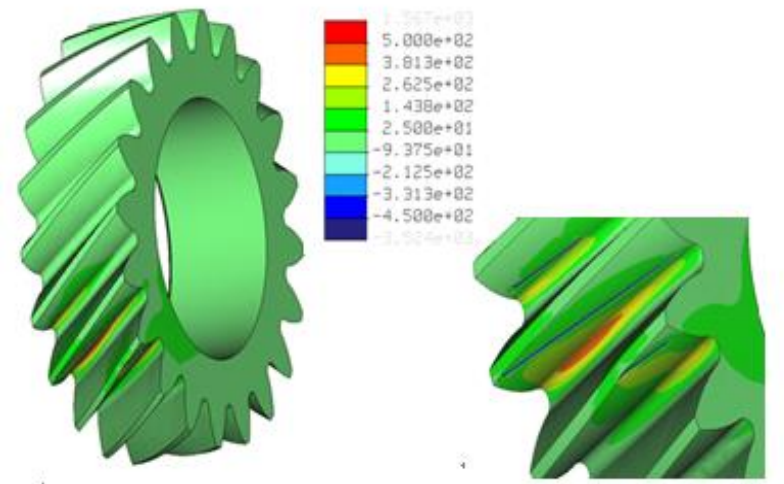

Fig. 9. Distribution of tooth root stress of dedendum single circular gear

\subsection{Analysis and comparison of bending stress in different meshing locations}

Considering visibility of the pictures, only changes of bending stress at 9 rotation angle positions on the tangent were showed in Figs. 10 and 11, horizontal ordinate stands for tooth root tangent arc length from beginning to the end when meshing and vertical ordinate stands for Max principal stress. The stress is smaller in the mesh beginning and in a third arc long range in the direction of tooth width. But with gears meshing more, bending stress became bigger, then smaller. From the graph we can know that the maximum principal stress of dedendum double circular gears is about $406 \mathrm{MPa}$, while that of dedendum single circular gears is only 325 $\mathrm{MPa}$, the same as bending stress in some other meshing positions. Because in the actual meshing process of gears, the biggest bending stress does not necessarily occur on the tangent, so the maximum principal stress of the whole stress concentration area is calculated for comparison. Maximum principal stress of helical gears with different rotation angles are provide in Table 4.

With FEM, bending stress of the two kinds of gears at 18 positions corresponding to their rotation angles were worked out then a comparison chart was drawn according to the date in the table, as shown in Fig. 12. In the process of gear engagement, bending stress of the two kinds of gears has little changes, and curve fluctuation is small. But dedendum double circular gear's bending stress has bigger volatility in the rotation angle of $8^{\circ} \sim 14^{\circ}$, it may be caused by too small fillet curve curvature. And in the whole meshing process, the max bending stress of dedendum single circular gears is 1.3 1.5 times as that of the dedendum double circular gears, so a conclusion is gotten that compared with dedendum double circular gears, dedendum single circular gears has better carrying capability. 
Table 4 Maximum principal stress of helical gears with different rotation angles

\begin{tabular}{c|c|c}
\hline \multirow{2}{*}{ Rotation Angle } & \multicolumn{2}{|c}{ Maximum Principle Stress } \\
\cline { 2 - 3 } & Single fillet curves & Double fillet curves \\
\hline $0^{\circ}$ & $487.3 \mathrm{Mpa}$ & $689.1 \mathrm{Mpa}$ \\
\hline $3^{\circ}$ & $483.4 \mathrm{Mpa}$ & $688.4 \mathrm{Mpa}$ \\
\hline $6^{\circ}$ & $490.3 \mathrm{Mpa}$ & $700.6 \mathrm{Mpa}$ \\
\hline $9^{\circ}$ & $498.1 \mathrm{Mpa}$ & $727.2 \mathrm{Mpa}$ \\
\hline $12^{\circ}$ & $473.2 \mathrm{Mpa}$ & $632.1 \mathrm{Mpa}$ \\
\hline $15^{\circ}$ & $457.2 \mathrm{Mpa}$ & $675.4 \mathrm{Mpa}$ \\
\hline $18^{\circ}$ & $466.0 \mathrm{Mpa}$ & $668.1 \mathrm{Mpa}$ \\
\hline
\end{tabular}

\begin{tabular}{|l|l|l|l|l|l|}
\hline & Stres Max Prin(WCS) \\
\hline
\end{tabular}

Fig. 10. Gear root stress results of dedendum with double circular curves

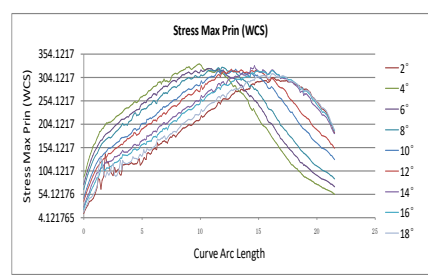

Fig. 11. Gear root stress results of dedendum with single circular curves

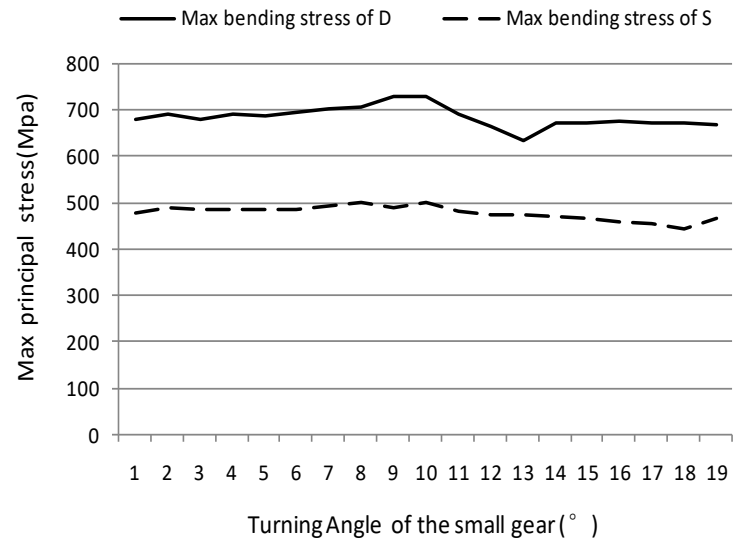

Fig. 12. Comparison of Max principal stress of helical gears

\section{Conclusions}

This work presents an analytical method about several gear teeth that contacting with each other in space simultaneously. First, the software Pro/ENGINEER was applied to establish two kinds of modified helical gears whose fillet curves are typical double circulars and single circular. Second, changes of meshing positions were made to get directional contact analysis results, so the results are reliable and authoritative. In the end a conclusion was proved that through analysis and comparison, tooth root stress of dedendum double circular gears is 1.3 1.5 times as that of dedendum single circular gears, that is dedendum single circular gears has better carrying capacity.

\section{Acknowledgment}

The authors are grateful for the technical support from Prof. Zhonghou Wang at the University of Shanghai for Science and Technology.

\section{Conflict of Interest Statement}

The authors declare that there is no conflict of interest in the study.

\section{CRediT Author Statement}

Gang Li: Conceptualization, Supervision, Writing-original draft, Writing-review \& editing, Validation,

Zhi Geng: Data curation, Software

\section{Nomenclature}

$r_{b} \quad:$ Base radius of the contact point $(\mathrm{mm})$

$r_{c} \quad$ : Profile radius of the contact point $(\mathrm{mm})$

$z \quad:$ Number of teeth

$\alpha_{c} \quad$ : Pressure angle at the contact point (deg)

$\alpha_{n} \quad$ : Normal pressure angle (deg)

$\alpha_{t} \quad:$ Transverse pressure angle (deg)

$\chi \quad$ : Addendum coefficient 


$\begin{array}{ll}\xi_{c} & : \text { Profile parameter of the contact point } \\ U & : \text { Elastic potential energy } \\ F & : \text { Normal load }(\mathrm{N}) \\ P & : \text { Transmitted power }(\mathrm{W}) \\ \omega & : \text { Angular velocity of the pinion }(\mathrm{rpm}) \\ B & : \text { Tooth width }(\mathrm{mm}) \\ E & : \text { Modulus of elasticity }\end{array}$

\section{References}

[1] Kulkarni M, Shim T, Zhang Y. Shift dynamics and control of dualclutch transmissions. Mech Mach Theory. 2007;42(2):168-182.

[2] Hu YH, Li G, Zhu WD, Cui JK. An elastic transmission error compensation method for rotary vector speed reducers based on error sensitivity analysis. Appl Sci. 2020;10(2):481.

[3] Yan J, Li G, Liu K. Development trend of wind power technology. Int J Adv Eng Res Sci. 2020;7(6):124-132.

[4] Srivastava N, Haque I. Transient dynamics of metal V-belt CVT: Effects of band pack slip and friction characteristic. Mech Mach Theory. 2008;43(4):459-479.

[5] Li G. Design and modeling of an impulse continuously variable transmission with a rotational swashplate. Int J Auto Sci Tech. 2020;4(4):307-313.

[6] Xu M, Zhang X, Hu G, Li G. The structure design and flow field simulation of a fire water monitor driven by worm gear with bevel gear. Mach Tool \& Hydra. 2016;6:57-61.

[7] Gu KL, Wang ZH, Li G, Liu XR. Optimization of geometric parameters of the straight conjugate internal gear pump based on GA. Elec Sci Tech, 2017;30(6):39-42.

[8] Zhang XL, Wang ZH, Li G. Research on virtual hobbing simulation and study of tooth surface accuracy of involute helical gears. Appl Mech Mater. 2012;155:601-605.

[9] Li G, Wang ZH, Zhu WD, Kubo A. A function-oriented active formgrinding method for cylindrical gears based on error sensitivity. Int J Adv Manuf Tech. 2017;92(5-8):3019-3031.

[10]Wang ZH, Zhu WM, Li G, Geng Z. Optimization of contact line for form-grinding modified helical gears based on neural network. China Mech Eng. 2014;25(12):1665-1671.

[11]Li G. An active forming grinding method for cylindrical involute gears based on a second-order transmission error model. SCIREA J Mech Eng. 2019;2(1):1-14.

[12]Li G, Zhu WD. An active ease-off topography modification approach for hypoid pinions based on a modified error sensitivity analysis method. ASME J Mech Des. 2019;141(9):093302.

[13]Li G, Wang ZH, Kubo A. Error-sensitivity analysis for hypoid gears using a real tooth surface contact model. Proc Instn Mech Eng, Part C: J Mech Eng Sci. 2017;231(3):507-521.

[14]Zhang WX, Wang ZH, Liu XR, Li G, Wan PL, Wang W. Research on optimization of temperature measuring point and thermal error prediction method of CNC machine tools. J Shaanxi University of Tech (Na Sci Ed). 2017; 33(3):18-24.

[15]Wang ZH, Cao H, Li G, Liu XR. Compensation of the radial error of measuring head based on forming grinding machine. J Mech Trans. 2017;41(3):143-146.
[16]Wang ZH, Song XM, He WM, Li G, Zhu WM, Geng Z. Tooth surface model construction and error evaluation for tooth-trace modification of helical gear by form grinding. China Mech Eng. 2015;26(21):2841-2847.

[17]Li G, Wang ZH, Kubo A. Tooth contact analysis of spiral bevel gears based on digital real tooth surfaces. Chin J Mech Eng. 2014;50(15):111.

[18]Wang ZH, Wang J, Ma PC, Li G. Dynamic transmission error analysis of spiral bevel gears with actual tooth surfaces. J Vib Shock. 2014;33(15):138-143.

[19]Wang ZH, Wang J, Wang QL, Li G. Transmission error of spiral bevel gear based on finite element method. J Vib Shock. 2014;33(14):165-170.

[20]Li G, Wang ZH, Kubo A. The modeling approach of digital real tooth surfaces of hypoid gears based on non-geometric-feature segmentation and interpolation algorithm. Int $\mathbf{J}$ Prec Eng Manuf. 2016;17(3):281-292.

[21]Li G, Zhu WD. Design and power loss evaluation of a noncircular gear pair for an infinitely variable transmission. Mech Mach Theory. 2021;156:104137.

[22]van Berkel K, Hofman T, Vroemen B, Steinbuch M. Optimal control of a mechanical hybrid powertrain. IEEE Trans Vehic Tech. 2012;61(2):485-497.

[23]Huang DQ, Wang ZH, Li G, Zhu WD. Conjugate approach for hypoid gears frictional loss comparison between different roughness patterns under mixed elastohydrodynamic lubrication regime. Tribo Int. 2019;140:105884.

[24]Li G, Wang ZH, Zhu WD. Prediction of surface wear of involute gears based on a modified fractal method. ASME J Tribo. 2019;141(3):031603.

[25]Wu J, Wang ZH, Li G. Study on crack propagation characteristics and remaining life of helical gear. J Mech Trans. 2014;38(12):1-4.

[26]Wan GQ, Huang Y, Zhang FJ, Li G. Integrated powertrain control for gear shifting. Appl Mech Mater. 2012;148:725-730.

[27]Li G, Wang ZH, Geng Z, Zhu WM. Modeling approach of digital real tooth surfaces of hypoid gears based on non-geometric-feature segmentation and interpolation algorithm. Chin J Mech Eng. 2015;51(7):77-84.

[28]Li G, Geng Z. Tooth contact analysis of herringbone rack gears of an impulse continuously variable transmission. Int J Auto Sci Tech. 2021;5(1):52-57.

[29]Wang ZH, Yuan KK, Li G. Optimization identification for dynamic characteristics parameters of sliding joints based on response surface methodology. China Mech Eng. 2016;27(5):622-626.

[30] Hu YH, Li G, Hu AM. Iterative optimization of orbital dynamics based on model prediction. Front Arti Intel App. 2019;320:76-86. 